\title{
Médicos, enfermeras y pacientes: entre las contradicciones, la incertidumbre y las carencias en tiempo de covid-19 en México*
}

\author{
Doctors, nurses and patients: dealing with contradictions, \\ uncertainty and shortages during covid-19 in Mexico
}

\author{
Claudia Agostoni ${ }^{i}$ \\ ' Investigadora Titular, Instituto de \\ Investigaciones Históricas/Universidad \\ Nacional Autónoma de México. \\ Ciudad de México - México \\ orcid.org/0000-0001-9186-3028 \\ agostoni@unam.mx
}

Recebido em 23 set. 2020. Aprovado em 25 set. 2020.
AGOSTONI, Claudia. Médicos, enfermeras y pacientes: entre las contradicciones, la incertidumbre y las carencias en tiempo de covid-19 en México. História, Ciências, Saúde - Manguinhos, Rio de Janeiro, v.28, n.3, jul.-set. 2021, p.863-867.

\section{Resumen}

La pandemia de covid-19 puso al descubierto las innumerables carencias que durante décadas han formado parte del inequitativo y fragmentado sistema nacional de salud. Las siguientes reflexiones tienen como propósito central enunciar la fragilidad en la que labora el personal de salud en México, al igual que las contradictorias declaraciones que han acompañado el desarrollo de la pandemia en el país, una conjunción de elementos que han acentuado la incertidumbre frente a la nueva enfermedad y su manejo.

Palabras clave: personal de salud; carencias; contradicciones; pacientes; México.

\section{Abstract}

The covid-19 pandemic revealed the innumerable shortages that have characterized the nation's inequitable and fragmentary health care system for decades. The main goal of the following reflections is to outline the precarity of working conditions for health care personnel in Mexico, as well as the contradictory statements issued as the epidemic developed in the country, a combination of factors that magnified uncertainty about the new disease and how to deal with it.

Keywords: health care workers; shortages; contradictions; patients; Mexico. 
$\mathrm{M}$ últiples han sido las reacciones y respuestas que ha generado la pandemia de covid-19 a nivel internacional, siendo la incertidumbre el común denominador. En México, el desasosiego se ha acentuado debido a la profunda desarticulación y precariedad que desde décadas atrás prevalece en el fragmentado e inequitativo sistema nacional de salud, a causa, también, de los contradictorios comunicados del Poder Ejecutivo, de la Secretaría de Salud y de las autoridades estatales y municipales, al igual que por las maneras en la que se han dado a conocer las cifras de enfermos y fallecimientos, entre otros elementos.

Si bien es de celebrar que diariamente la Secretaría de Salud informa sobre el progreso de la pandemia, es relevante hacer notar que lo que se ha privilegiado es la terminología y los conceptos procedentes de la vigilancia epidemiológica, lo que lamentablemente no ha sido consistente y tampoco claro para el público en general. Además, el énfasis con el que las autoridades de salud han intentado reafirmar la veracidad de las cifras que proporcionan desde que se registró el primer caso de covid-19 en la Ciudad de México, se ha desdibujado y debilitado debido a que México sobresale entre los países que menos pruebas aplica para identificar a los enfermos y a los posible portadores de la nueva enfermedad. Así, al 11 de septiembre las cifras oficiales, las que han sido ampliamente cuestionadas por diferentes organismos e instituciones nacionales y del extranjero, dieron a conocer que el país acumulaba más de 70 mil fallecimientos y 658 mil contagios, lo que ubicó a México como uno de los países con el más elevado índice de letalidad a nivel global (México..., 2020).

El 27 de febrero, después de varias semanas de rumores, noticias y comunicados encontrados, las autoridades de salud confirmaron la hospitalización del primer paciente con SARS-CoV-2 en la Ciudad de México. De entonces a la fecha, los comunicados del sector salud, del titular del Poder Ejecutivo y de los gobiernos de los estados, han estado en constante contradicción. Así, mientras que el presidente Andrés Manuel López Obrador (AMLO) sostenía el 29 de febrero que el nuevo virus no era "ni siquiera equivalente a la influenza" (El pánico..., 29 feb. 2020), también aseguraba que la honestidad y la lucha contra la corrupción de su gobierno eran la mejor protección. De igual forma, además de mostrar amuletos, una imagen del Sagrado Corazón, y de pronunciar las siguientes palabras en aras de la contención de la pandemia: "Detente enemigo, que el corazón de Jesús está conmigo..." (AMLO..., 18 mar. 2020), los funcionarios estatales y el personal de la Secretaría de Salud trabajaban en el diseño para implementar un programa de distanciamiento social. Las medidas entraron oficialmente en vigor el 23 de marzo, iniciando la llamada "jornada nacional de sana distancia", lo que llevó a la suspensión de todas las actividades calificadas como "no esenciales" en los sectores público, social y privado, reiterándose que era fundamental que la población se quedara en casa.

Entre ese día de marzo y el 1 junio, cuando inició la llamada "nueva normalidad", lo que se acompañó de una tendencia ascendente de casos confirmados, sospechosos y de fallecimientos, el titular del Poder Ejecutivo prosiguió minimizando las recomendaciones del sector salud. Realizó eventos públicos y giras, uno de éstos al estado de Sinaloa donde saludó a la señora María Consuelo Loera, madre del narcotraficante Joaquín el Chapo Guzmán Loera (En su visita..., 29 mar. 2020). También reiteró en diferentes ocasiones que en México la pandemia ya había sido "domada". Por otra parte, el subsecretario de Promoción y Prevención de la Salud, el doctor Hugo López-Gatell ha manifestado amplias 
reservas respecto de la pertinencia de realizar pruebas diagnósticas y ha subestimado la importancia que reviste el uso sistemático del cubrebocas, argumentando que "no hay evidencia científica útil" y que ordenar su uso podría generar "riesgos de abuso a los derechos humanos y tensión social" (Navarro, 12 ago. 2020). Además, la politización del uso del cubrebocas llevó a que el titular del Poder Ejecutivo afirmara lo que sigue el 31 de julio: "Me pondré un cubrebocas cuando no haya corrupción" (Me voy..., 31 jul. 2020).

Aunado a los contradictorios comunicados procedentes del sector salud y del titular del Poder Ejecutivo, han sido constantes las demandas, protestas, reclamos y exigencias de parte del personal médico y de enfermería de distintos hospitales a lo largo del país. Cotidianamente, en las conferencias de prensa en la que se informa sobre el curso de la pandemia, las autoridades federales de salud celebran los esfuerzos realizados en materia de reconversión hospitalaria, y se insiste en subrayar que se ha logrado aumentar el número de camas y ventiladores para pacientes con SARS-CoV-2. Sin embargo, las exigencias del personal médico, de enfermería y de intendencia han visibilizado la persistente ausencia de protocolos claros y específicos para la atención de los pacientes y de sus familias, la falta de equipo básico de protección personal, la inexistencia del más elemental material sanitario, y sobre todo, las frágiles e inseguras condiciones laborales en la que se desempeña el personal sanitario. Así lo expresó un grupo de enfermeras del Hospital General Regional Número 1 el 20 de marzo, y una semana después hizo lo mismo el personal de salud del Centro Médico Nacional La Raza, ambos adscritos al Instituto Mexicano del Seguro Social (IMSS) en la Ciudad de México (Poy Solano, 20 mar. 2020; Camacho Servín, 27 mar. 2020). Cabe destacar que las exigencias y las protestas no han cesado desde el mes de marzo en todo el país.

Es importante señalar que las demandas y manifestaciones del personal de salud también fueron constantes a lo largo de 2019. Durante ese año, antesala de la pandemia, numerosos médicos y médicas, al igual que enfermeras y enfermeros de hospitales federales, de la seguridad social y de los institutos nacionales de salud, entre otros, repetidamente tomaron las calles, suspendieron sus labores de manera escalonada y reclamaron la creciente precariedad en la que se veían obligados a trabajar a causa de los incesantes recortes presupuestales en el sector salud. La suspensión de pagos ordinarios y extraordinarios por horas extra, guardias y suplencias; la falta de equipos e insumos hospitalarios; la disminución y reprogramación de cirugías, consultas médicas y servicios médicos generales; las afectaciones en el abasto de medicamentos y de material de curación, fueron algunos de los motivos de los reclamos y protestas. Asimismo, miles de pacientes, solos o con sus familias, tomaran las calles y avenidas de las ciudades principales exigiendo al sector salud continuidad en los tratamientos, seguimiento de las consultas médicas y fin a la escasez de medicamentos.

La intensificación de la precariedad e inequidad en el fragmentado sistema de salud a lo largo de 2019, cuyos orígenes anteceden a las reformas neoliberales de la década de 1980, han provocado que México sea uno de los países con el menor grado de inversión en el sector salud a nivel internacional. Lo anterior se refleja en el escaso personal médico, de enfermería y de camas hospitalarias, entre otros indicadores. Por ejemplo, si bien en 2017 el promedio de médicos, personal de enfermería y camas hospitalarias de los países que 
forman parte de la Organización para la Cooperación y el Desarrollo Económico (OCDE), de la que México forma parte, se ubicó en 3,5 médicos, 8,8 de personal de enfermería y 4,7 camas hospitalarias por cada mil habitantes, en 2019 esos indicadores solo para el caso de México fueron aún menores: 2,4 médicos por cada mil habitantes, tanto del sector público como privado, 2,9 de personal de enfermería por cada mil habitantes y 1,4 cama por cada mil habitantes (OCDE, 2019).

Fue el 6 de abril de 2020 cuando las autoridades reconocieron que el país contaba con un déficit de por lo menos 120.000 médicos y enfermeras(os) para hacer frente a la pandemia. Para subsanar lo anterior, la Secretaría de Salud y el IMSS emitieron una convocatoria para contratar a 6.600 doctores y a 12.300 enfermeras(os) en dos semanas, asegurando que el personal contratado obtendría una adecuada y pronta capacitación y que contaría con el equipo requerido para la atención hospitalaria. Sin embargo, el personal contratado se ha enfrentado a una profunda desorganización, a la demora en los pagos y en la firma de contratos con diferentes hospitales de la Ciudad de México, Sinaloa y Oaxaca, y a la falta de equipo de protección personal. La precariedad en la que labora el personal de salud ha llevado a que México sea uno de los países, a nivel global, con el mayor número de muertes entre el personal médico y de enfermería a causa de la covid-19; un personal que también ha enfrentado represalias, arrestos, detenciones, amenazas y despidos al expresar o hacer públicas sus demandas y las condiciones en las que trabajan (Contratados..., 17 jun. 2020; Agren, 19 sep. 2020, p.807).

Por otra parte, fue desde marzo cuando se comenzaron a registrar expresiones y manifestaciones de enojo, violencia física y verbal, desprecio y miedo hacia el personal médico y de enfermería. Si bien los motivos de la descalificación y de las agresiones por parte del público y de los pacientes hacia el personal de salud pueden explicarse por el miedo que históricamente ha generado la propagación de múltiples enfermedades colectivas, y por los rumores y noticias que incitan a dudar de la veracidad de la existencia y propagación de la nueva enfermedad, es importante destacar que en México la erosión de la confianza entre el personal de salud, los pacientes, el público y las instituciones tiene una larga historia. La conflictiva y precaria coyuntura en la que se encuentra el sector salud, la frecuente descalificación y la poca valoración social y cultural de las labores que históricamente ha desempeñado el heterogéneo personal de salud, son algunos de los elementos que pueden contribuir a explicar el por qué de esas violencias. La propagación del virus SARS-CoV-2 ha puesto al descubierto e intensificado las múltiples limitaciones y carencias de larga data en las que opera y en las se desenvuelve cotidianamente el fragmentado sistema nacional de salud, lo que cada día adquiere mayor visibilidad y resonancia.

\section{NOTA}

* El siguiente texto es una versión más completa, actualizada y sometida a revisión de pares de un post que apareció en el blog de História, Ciências, Saúde - Manguinhos. 


\section{REFERENCIAS}

AGREN, David. Understanding Mexican health workers covid-19 deaths. The Lancet, v.396, p.807, 19 sep. 2020. Disponible en: https://www. thelancet.com/journals/lancet/article/PIIS01406736(20)31955-3/fulltext. Acceso en: 19 sep. 2020.

AMLO usará "El Detente", símbolo católico para contener al coronavirus y otros males en México. Economíahoy.mx, 18 mar. 2020. Disponible en: https://www.economiahoy.mx/ nacional-eAm-mx/noticias/10425624/03/20/ AMLO-usara-El-Detente-simbolo-catolicopara-contener-al-coronavirus-y-otros-males-enMexico-.html. Acceso en: 22 feb. 2021.

CAMACHO SERVÍN, Fernando. Protesta personal de Centro Médico la Raza por carencias ante covid-19. La Jornada, 27 mar. 2020. Disponible en: https://www.jornada.com.mx/ ultimas/sociedad/2020/03/27/protesta-personalde-centro-medico-la-raza-por-carencias-antecovid-19-8706.html. Acceso en: 19 sep. 2020.

CONTRATADOS por Insabi ante emergencia de covid-19 denuncian retraso en pagos, desorganización y falta de seguros. Animal Político, 17 jun. 2020. Disponible en: https:// www.animalpolitico.com/2020/06/insabicontratados-malas-condiciones-laborales-covid. Acceso en: 19 sep. 2020.

EL PÁNICO no se justifica, AMLO. La Jornada, 29 feb. 2020. Disponible en: https://www.jornada. com.mx/2020/02/29/politica/003n1pol. Acceso en: 22 feb. 2021.

EN SU VISITA a Badiraguato, AMLO saludó a la mamá del Chapo Guzmán. Aristegui Noticias, 29 mar. 2020. Disponible en: https:// aristeguinoticias.com/2903/mexico/en-su-visitaa-badiraguato-amlo-saludo-a-la-mama-delchapo-guzman-video. Acceso en: 19 sep. 2020.

ME VOY a poner cubreboca cuando no haya corrupción: AMLO. Animal Político, 31 jul. 2020. Disponible en: https://www.animalpolitico. com/2020/07/me-voy-a-poner-cubrebocacuando-no-haya-corrupcion-amlo-amparo-pan. Acceso en: 1 sep. 2020.

MÉXICO suma 534 muertes por covid-19 y supera las 70 mil defunciones. Animal Político, 11 sep. 2020. Disponible en: https://www. animalpolitico.com/2020/09/mexico-70-mildefunciones-covid-19. Acceso en: 1 sep. 2020.

NAVARRO, María Fernanda. Obligar uso de cubrebocas pone en riesgo derechos humanos: López-Gatell. Forbes México, 12 ago. 2020. Disponible en: https://www.forbes.com.mx/ politica-obligar-cubrebocas-riesgo-derechoshumanos-lopez-gatell. Acceso en: 19 sep. 2020.

OCDE, Organización de Cooperación y Desarrollo Económico. Estadísticas en salud de México. Actualización de Estadística de la Organización de Cooperación y Desarrollo Económico, 2019. Disponible en: https:// codigof.mx/estadisticas-en-salud-de-mexicoactualizacion-de-estadisticas-de-salud-de-laocde-2019. Acceso en: 19 sep. 2020.

POY SOLANO, Laura. Enfermeras de hospital del IMSS protestan por falta de insumos. La Jornada, 20 mar. 2020. Disponible en: https://www. jornada.com.mx/ultimas/sociedad/2020/03/20/ enfermeras-de-hospital-del-imss-protestan-porfalta-de-insumos-7281.html. Acceso en: 29 mar. 2020. 